\title{
How Small is Zero Price? The True Value of Free Products
}

\author{
Kristina Shampan'er and Dan Ariely
}

\begin{abstract}
When faced with a choice of selecting one of several available products (or possibly buying nothing), a standard theoretical perspective suggests that the option with the highest benefitcost difference will be chosen. This analysis applies to all prices including the price of zero. In contrast, we propose that decisions about free products are different than simply subtracting costs from benefits, and that in fact the benefits associated with free products are perceived to be higher. We test this idea by contrasting the demands for two products (types of chocolate) across conditions that maintain the cost-benefit difference for the goods, but vary on whether the price of the cheaper good in the set is priced at a low positive price or at zero. Contrary to a standard cost-benefit perspective, the results show that, in the zero-price condition, the proportion of participants choosing the less attractive chocolate dramatically increases, while the proportion of participants choosing the more attractive chocolate dramatically decreases. Thus, individuals seem to act as if pricing a good as free not only decreases its cost, but also adds to its benefits. After documenting this basic effect, we propose and test several possible psychological antecedents of the effect: Social norms, Mapping difficulty, and Affect. The results suggest Affect as the most likely source of the effect.
\end{abstract}

JEL Classifications: C93, D40, Z0

Dan Ariely is the Alfred P. Sloan Professor of Behavioral Economics at MIT and a visiting scholar at the Federal Reserve Bank of Boston's Research Center for Behavioral Economics and Decision-Making. His email address is ariely@mit.edu. Kristina Shampan'er is a PhD candidate at MIT.

This paper, which may be revised, is available on the web site of the Federal Reserve Bank of Boston at http://www.bos.frb.org/economic/wp/index.htm.

The views expressed in this paper are those of the authors and do not necessarily represent the views of the Federal Reserve Bank of Boston or the Federal Reserve System.

This version: October 2006

RESEARCH CENTER FUR BEHAVIORAL ELINGMICS AND DECISIGN-MAKING 
"The point about zero is that we do not need to use it in the operations of daily life. No one goes out to buy zero fish. It is in a way the most civilized of all the cardinals, and its use is only forced on us by the needs of cultivated modes of thought."

Alfred North Whitehead

Initially invented by Babylonians, not as a number but as a placeholder, the concept of zero and void was feared and denied by Pythagoras, Aristotle, and their followers for centuries. The most central objection of the early Greeks to zero was based on religious beliefs. They argued that God was infinite and that, therefore, void (zero) was not possible. In addition to the religious arguments, the early Greeks did not recognize the need for zero, since their mathematics was based on geometry, and, thus, zero and negative numbers were not important to their thought. Yet, their failure to adopt the concept of zero is likely to have been the block that impeded them from discovering calculus and slowed the development of mathematics for centuries.

The concept of zero as a number was brought to India by Alexander the Great, and this is where it was first accepted. In India-unlike the situation in Greece, where algebra was separated from geometry - infinity and void were a part of the same system of beliefs (destruction, purity, and the facilitation of new beginnings), and the concept of zero flourished. The notion of zero later found its way into Arabia and was later exported to Europe. Yet, because Aristotle had not accepted zero, and because Christianity was partially based on Aristotelian philosophy and Aristotle's "proof of God," zero was not widely embraced by the Christian world until the sixteenth century. ${ }^{1}$

In more recent history, the concept of zero has made its way into our understanding of multiple aspects of human psychology, demonstrating that, in more than one domain, zero is used in a qualitatively different manner from other numbers; and the transition from small positive numbers to zero is often discontinuous.

Starting with cognitive dissonance theory (Festinger and Carlsmith, 1959), it has been shown that getting zero reward for performing a task, compared with getting a small positive reward, can increase the desirability of the task. Later work has shown

\footnotetext{
${ }^{1}$ For a good source about the history of zero, see: Seife, C. (2000). Zero, The Biography of a Dangerous Idea. Penguin Books, New York.
} 
that changing the reward from something to nothing can influence motivation (Festinger and Carlsmith, 1959) and self-perception (Bem, 1965), change motivation from intrinsic to extrinsic (Lepper, Greene, and Nisbett, 1973), and alter feelings of competence and control (Deci and Ryan, 1985). For example, Gneezy and Rustichini (2000a) demonstrated that introducing a penalty for parents who are late in picking up their kids from kindergarten can actually increase tardiness. Similarly, Gneezy and Rustichini (2000b) found that, while performance in tasks such as IQ tests or collecting money for charity increased as expected with the size of a positive piece-wise reward, the exception to this mode was zero reward, where, in fact, performance was higher when no reward was mentioned than when a small reward was offered.

Related to these findings on motivation and incomplete contracts, it has also been shown that when prices are mentioned, individuals apply market norms, while when prices are not mentioned (that is, when the price is effectively zero), individuals apply social norms to determine their choices and effort (Heyman and Ariely, 2004). As an illustration of this idea, Ariely, Gneezy, and Haruvy (2005) have shown that when Starburst candy is offered at a cost of $1 \$$ per piece, an average MIT student is likely to take about four pieces, whereas when the price is zero, more students will take some, but almost no-one will take more than one (effectively creating a decreased demand when prices are reduced).

Finally, in a different domain, clearly the most influential research on the psychology of zero is rooted in Kahneman and Tversky's (1979) work on probabilities. This original work, and the voluminous papers that followed it, showed that when it comes to gambles, zero probability (as well as certainty) is perceived as substantially different from small positive probabilities. That is, whereas the values of the latter are perceived as higher than they actually are, the perception of zero probability is accurate.

In the current work, we extend the research on the psychology of zero to pricing and examine the psychology of "free." In a series of experiments, we demonstrate that when people are faced with a choice between two products, one of which is free, they "overreact" to the free product as if zero price meant not only a low cost of buying the 
product, but also increased consumers' valuation of the product itself. In section 1 we describe a method that can be used to examine reaction and overreaction to free products. In section 2 we describe two formal models: one that treats the price of zero as any other price, and one that includes a unique role for the price of zero. The contrasts between these two models provide some predictions of the effects of price reductions on demand. In section 3 we report experimental evidence that tests these predictions and supports the zero-price model. In section 4 we take a first step in the direction of finding and testing the psychological causes that bring about the effect of zero price. We end with general conclusions and some questions for future directions.

\section{Measuring Reaction/Overreaction to Zero Price}

One method that could be used to determine whether people overreact to free products is simply to test whether consumers take more of a product when it is free than buy the product when it has a very low price (for example, 1\$). However, while such behavior would be consistent with overreaction to zero price, it could simply reflect an increase in demand when prices decrease. Similarly, it is not sufficient to show that the increase in demand when price is reduced from $1 \$$ to zero is larger than the increase in demand when the price is reduced from $2 \phi$ to $1 \phi$, because such a pattern of behavior could simply reflect a demand structure that is non-linear in price (created, for example, by a valuation distribution where more people value the product between $0 \$$ and $1 \$$ than value it between $1 \$$ and $2 థ)$.

In order to measure reaction to zero in a way that overcomes these possible alternative interpretations, we examine whether individuals would select a free product even when this means that they would forgo an option that they "should" find preferable. To create such a test, we use a setup that contrasts two choice situations with a constant difference between two products' net benefits, and use aggregate preference inconsistency as a measure of overreaction to the free product. The basic structure of this approach (and of our experiments) is the following: All subjects are offered a choice among three options: buy a low-value product (for example, one Hershey's Kiss, or 
"Hershey's" for short); buy a higher-value product (for example, one Lindt truffle or "Lindt"); or buy nothing. The variation across conditions that allows us to measure the reaction to the price of zero is based on two basic conditions: "cost" and "free." In the cost condition, the prices of both products are positive (for example, Hershey's is offered for $1 \$$ and Lindt for $14 \$)$. In the free condition, both prices are reduced by the same amount, so that the cheaper good becomes free (for example, Hershey's is offered for free, and Lindt is offered for $13 \$)$.

To understand better how this setup could be useful in testing whether the price of zero has some added attraction, let us consider how such constant price reductions might influence the demands for the two products in a model in which zero is particularly attractive and a model in which zero is "just another price." From the perspective of a model where the price of zero is particularly attractive, a price reduction from the cost condition to the free condition would create a boost in the attractiveness of the low-value product and hence increase its relative demand. On the other hand, from the perspective of a model in which zero is "just another price," since all changes in prices are the same, reducing the price of the low-value product to zero does not create any unique advantage for that product. In the next section we examine these two models more formally and provide some testable predictions for distinguishing between them.

\section{A Formal Account of a Standard Economic Model and the Zero Price Model}

In this section we describe a "standard" model of how consumers behave in a situation where they have to choose between two products at certain prices (or buy nothing), and how their choices would change if both prices were reduced by the same amount. We then consider a special case of this situation, when the price decrease is equal to the original smaller price; that is, the new smaller price is zero. For this

particular situation we contrast the standard model with the "zero-price model." The latter model is identical to the former in all respects, except that it assumes that, when a 
product becomes free, the product's intrinsic value for consumers (or benefit, in the costbenefit terminology) goes up. We then show how the predictions of the two models about the observable behavior of consumers differ; in the third section, we test these predictions empirically.

Consider a model with linear utilities in which a consumer has to choose among three options, $\mathrm{X}, \mathrm{Y}$, and $\mathrm{N} .^{2}$ Option $\mathrm{X}$ is buying one unit of product $\mathrm{X}$, priced at $\mathrm{Px}$; option $\mathrm{Y}$ is buying one unit of product $\mathrm{Y}$, priced at $\mathrm{P} Y$; option $\mathrm{N}$ is buying nothing. Suppose that the consumer values the first product at $\mathrm{Vx}$, and the second product at VY. Then, the consumer will choose $X$ if and only if

$$
\mathrm{Vx}>\mathrm{Px} \text { and } \mathrm{Vx}-\mathrm{Px}>\mathrm{V}_{\mathrm{Y}}-\mathrm{P}_{\mathrm{Y}}{ }^{3}
$$

The consumer will choose $\mathrm{Y}$ if and only if

$$
V_{Y}>P_{Y} \text { and } V_{Y}-P_{Y}>V_{X}-P_{X} .
$$

Finally, the consumer will buy nothing (choose N) if and only if

$$
\mathrm{VX}<\mathrm{Px} \text { and } \mathrm{V}_{\mathrm{Y}}<\mathrm{P}_{\mathrm{Y}}
$$

Assume now that there are multiple consumers with $\left[V_{x}, V_{Y}\right]$, where $V_{x}$ and $V_{Y}$ are both somehow distributed over the real numbers; then the three sets of inequalities above will determine three groups of consumers each choosing one of the three options, $\mathrm{X}, \mathrm{Y}$, and N (see Figure 1a).

Now let us consider a situation where both prices are reduced by the same amount, $\varepsilon$. The new prices are then equal to $\left[P_{x}-\varepsilon, P_{Y}-\varepsilon\right]$. How do the demand segments change? With the new prices, consumers choosing $X$ are those with

$$
V_{X}>P_{X}-\varepsilon \text { and } V_{X}-P_{X}>V_{Y}-P_{Y}
$$

Consumers choosing $\mathrm{Y}$ are those with

\footnotetext{
2 We discuss the linearity assumption in detail later in the paper.

${ }^{3}$ Without loss of generality we may assume that the probability that any of these and subsequent expressions results in equality is zero.
} 


$$
V_{Y}>P_{Y}-\varepsilon \text { and } V_{Y}-P_{Y}>V_{X}-P_{X}
$$

Finally, consumers choosing $\mathrm{N}$ are those with

$$
\mathrm{VX}_{\mathrm{X}}<\mathrm{PX}-\varepsilon \text { and } \mathrm{V}_{\mathrm{Y}}<\mathrm{P}_{\mathrm{Y}}-\varepsilon \text {. }
$$

It is easy to see from comparing the two sets of formulas (or by inspecting Figure $1 b)$, that the consumers who originally chose $X$ will keep choosing $X$, and the consumers who originally chose $\mathrm{Y}$ will keep choosing $\mathrm{Y}$. Thus, according to this model, there should be no switching from one product to the other. The only two possible changes in demand are that some consumers who originally bought nothing will switch to $\mathrm{X}$ (those with $\mathrm{VX}_{\mathrm{X}}-\mathrm{Px}_{\mathrm{X}}>\mathrm{V}_{\mathrm{Y}}-\mathrm{P}_{\mathrm{y}}$ and $\mathrm{Px}-\varepsilon<\mathrm{Vx}<\mathrm{Px}$ ); and some other consumers who originally bought nothing will switch to $\mathrm{Y}$ (those with $\mathrm{V}_{Y}-\mathrm{P}_{Y}>\mathrm{VX}_{X}-\mathrm{Px}_{\mathrm{X}}$ and $\mathrm{P}_{Y}-\varepsilon<\mathrm{V}_{Y}<\mathrm{P}_{Y}$ ).

In short, according to this simple cost-benefit model, when prices go down by the same amount, the costs decrease by the same magnitude for both products, whereas the benefits of both products remain the same, and hence the net benefits increase by the same amount. As a result, this model predicts that when the prices of both products drop by the same amount, both demands will increase weakly (see Table 1).

Now let us consider a special case, when the price reduction, $\varepsilon$, is equal to the original smaller price, say $\mathrm{Px}_{\mathrm{x}}$ so that the prices drop from $\left[\mathrm{Px}_{\mathrm{x}} \mathrm{P}_{\mathrm{y}}\right]$ to $\left[0, \mathrm{Py}_{\mathrm{y}} \mathrm{Px}\right]$. If zero is just another price, then the predictions above are still valid. Translating these predictions to our setting, when prices are reduced from the cost condition to the free condition, the proportion of consumers choosing to buy each of the two products should increase weakly (see Figure 1c).

Next, consider the "zero-price model," which assumes that when a good becomes free, consumers attach a special value to it; that is, their intrinsic valuation of the good goes up, say by $\alpha$. In this model, unlike the case in the standard model, some consumers may switch from the more expensive good to the cheaper good. These are the consumers whose valuations of the products satisfy the set of inequalities below, where the first two inequalities imply the original choice of $Y$, and the second two inequalities lead to switching to $\mathrm{X}$ when its price is reduced to zero: 


$$
\begin{gathered}
\mathrm{V}_{Y}>\mathrm{P}_{Y} \\
\mathrm{~V}_{Y}-\mathrm{P}_{Y}>\mathrm{V}_{X}-\mathrm{PX} \\
\mathrm{V}_{X}+\alpha>0 \\
\mathrm{~V}_{X}+\alpha-\mathrm{PX}_{\mathrm{X}}>\mathrm{V}_{Y}-\mathrm{P}_{Y} .
\end{gathered}
$$

That is, when the prices reduce from the cost condition to the free condition, the costs decrease by the same magnitude for both products, but the benefit of the now-free product increases more than the benefit of the more expensive product, and hence, the net benefit of the cheaper product becomes higher than the net benefit of the more expensive product. In terms of demand, the zero-price model predicts that as prices are reduced from the cost condition to the free condition, the demand for the cheaper good will increase, and, more importantly, the demand for the more expensive good may decrease as consumers switch from the more expensive product to the cheaper one (see Table 1 and Figure 1d). We call the combination of the increase in the proportion of consumers choosing $\mathrm{X}$ with the decrease in the proportion choosing $\mathrm{Y}$ when prices go down from $\left[\mathrm{Px}, \mathrm{P}_{Y}\right]$ to $\left[0, \mathrm{Py}_{\mathrm{Y}} \mathrm{Px}\right]$, the zero-price effect. Note that the prediction regarding the decrease in demand for the more expensive good is the single observable difference between the two models, and thus the empirical section will focus on this prediction. As will be seen in the following sections, this prediction of the zero-price model is, in fact, supported.

\section{Testing the Phenomenon}

In this section we describe a series of experiments designed to test the validity of the zero-price model, and to rule out some trivial economic explanations for the changes in demand that take place when the price of the cheaper good decreases to zero (from the cost condition to the free condition). 


\section{Experiment 1: Survey}

Method. Sixty participants were asked to make a hypothetical choice between a Hershey's, a Ferrero Rocher chocolate ("Ferrero" for short), and buying nothing (pictures of both chocolates were presented). Across the three conditions the prices of the two chocolates decreased by a constant amount (for a description of all conditions across all the experiments, see the appendix). In the cost condition, the prices of Hershey's and Ferrero were $1 \$$ and $26 \$$, respectively (1\&26 condition). In the free condition, both prices were reduced by $1 \$$, to $0 \$$ and $25 \$$, respectively ( $0 \& 25$ condition). The third condition ( $2 \& 27$ condition) was an additional cost condition in which the prices of the two goods were increased by $1 \$$ above their prices in the first cost condition. The purpose of the $2 \& 27$ condition was to contrast the effect of a 1 p price reduction that did not include a reduction to a price of zero (reduction from $2 \& 27$ to $1 \& 26)$ with a 1 \& price reduction that did involve a reduction to a price of zero (reduction from $1 \& 26$ to $0 \& 25)$.

Results and Discussion. The results can be seen in Figure 2. When the prices were decreased from the $1 \& 26$ condition to the $0 \& 25$ condition, the demand for Hershey's increased substantially [ $\mathrm{t}(31)=3.8, \mathrm{p}<0.001$, while, more importantly, the demand for Ferrero decreased substantially $[\mathrm{t}(31)=-2.3, \mathrm{p}=0.03]$, revealing the zeroprice effect. At the same time, the differences in demand between the $1 \& 26$ and $2 \& 27$ conditions were insignificant (for Hershey's $[t(38)=-0.3, p=0.76]$, for Ferrero $[t(38)=0, p$ $=1]$ ), demonstrating that when all the prices were positive, a $1 \$$ change in prices did not have a large effect on demand; only when one of the prices became zero did the observed perturbations take place. Thus, we observed a (hypothetical) behavior consistent with the zero-price model; participants reacted to the free Hershey's as if it, in fact, had an additional intrinsic value. 


\section{Experiment 2: Real Purchases}

While the results of Experiment 1 suggest that consumers react to a price decrease to zero differently from other price reductions, it is important to note that this was a reaction to a hypothetical situation; it is still an open question whether individuals would behave in the same way when faced with real transactions. As a secondary goal, Experiment 2 included another condition that was designed to test the robustness of the zero-price effect. In this condition, the price reduction was much larger for the high-end candy, giving participants a larger incentive to make choices opposite to the predictions of the zero-price effect. Another advantage of this unequal price reduction is that it provides a test of the notion that individuals divide, rather than subtract, costs and benefits, an idea that we will discuss later.

Method. There were 398 participants in the experiment. The two products used were a Hershey's as the low-value product and a Lindt as the high-value product. There was a free condition ( $0 \& 14)$, a cost condition (1\&15), and a second free condition (0\&10). In the $0 \& 14$ and $0 \& 10$ conditions, the price of Hershey's was $0 \notin$ in both conditions, and the price of Lindt was $14 \$$ and $10 \$$, respectively. In the $1 \& 15$ condition, the price of the Hershey's was $1 \$$ and the price of the Lindt was 15ф.

A booth was set up at MIT's student center with two cardboard boxes full of chocolates and a large upright sign that read "one chocolate per person." Next to each box of chocolates was a sign lying flat on the table that indicated the price of the chocolate in that condition. The flat signs could not be read from a distance, and the

prices were visible only to those standing close to the booth. We used the flat signs because we wanted to measure the demand distributions, including the number of people who considered the offer and decided not to partake. By placing the price signs flat next to the chocolates, we could count the people who looked at the prices but did not stop or did not purchase, classifying them as "nothing."

While field experiments have many advantages, one of the limitations of this particular setup was that the experimental conditions could not be randomized for each 
subject; instead, the price signs (conditions) alternated approximately every 45 minutes. When replacing the signs we wanted to reduce the chance that students would notice the change (thus mixing within- and between-subject designs); therefore, we made sure to leave a 15 -minute break between the 30 -minute experimental sessions.

Results and Discussion. As can be seen in Figure 3, the results were similar to the hypothetical choices in Experiment 1. When prices decreased from the $1 \& 15$ condition to the 0\&14 condition, the demand for Hershey's increased substantially $[\mathrm{t}(263)=5.6, \mathrm{p}<0.001]$, while the demand for Lindt decreased substantially $[\mathrm{t}(238)=-3.2$, $\mathrm{p}<0.01]$. In addition, there was no significant difference between the demand for the Hershey's in the 0\&14 condition and the demand for the Hershey's in the $0 \& 10$ condition $[\mathrm{t}(263)=0.5, \mathrm{p}=0.64]$, and the difference in demand for the Lindt between the $0 \& 14$ and $0 \& 10$ conditions was only marginally significant $[\mathrm{t}(271)=1.5, \mathrm{p}=0.13]$. Note, however, that this marginal difference was in the opposite direction from the expected effect of a price decrease on demand - a result that might be related to the higher number of participants who took nothing in the $0 \& 10$ condition.

Together these results show that the reduction of a price to zero is more powerful than a five-times-larger price reduction that is within the range of positive prices.

It is important to point out the somewhat surprisingly large proportion of people who selected "nothing." This observed lack of interest could be due to the way we coded the choice of "nothing"; some people who may have not even noticed the offers (and thus effectively not been part of the experiment) may have been misclassified as choosing "nothing" (instead of being considered non-participants). Another possible contributor to the choice of "nothing" may be transaction costs: Buying a chocolate or even taking a free chocolate requires attention and time. Finally, it is possible that in the experimental setting the value of chocolate was either not positive or not sufficiently large for our participants to choose one. If we take those who were coded as "nothing" out of the analysis, the share of Hershey's increases from 27 percent in the $1 \& 15$ condition to 69 percent in the $0 \& 14$ condition, and to 64 percent in the $0 \& 10$ condition. 
The demand for Lindt shows a complementary pattern, decreasing from 73 percent in the $1 \& 15$ condition to 31 percent in the $0 \& 14$ condition, and to 36 percent in the $0 \& 10$ condition. With this adjustment, the differences from the cost to the free conditions are statistically significant (both $\mathrm{p}>0.001$ ), while the differences between the two free conditions are not significant $[\mathrm{t}(142)=-1.0, \mathrm{p}=0.31]$.

In sum, the results of Experiment 2 demonstrate that valuations for free goods are boosted beyond their benefit-cost differences. This was shown with real transactions in a field setting and even in the case when the price drop of the high-value product was substantially larger than the price drop of the low-value product. The observed drop in demand for the high-value good in such a case (from the $1 \& 15$ condition to the $0 \& 10$ condition) is theoretically even more impossible in the standard economic model than it is when prices decrease by the same amount.

Another advantage of the comparison of the $0 \& 10,0 \& 14$, and $1 \& 15$ conditions is that it may shed some light on the possibility that, rather than evaluating options based on their benefit-cost difference, individuals may evaluate goods based on the ratio of the benefits to the costs (note that this is not a normative account). Under this interpretation, the "net value" of a free good would be very high (strictly speaking, infinite) and, therefore, demand for the free good should increase more than otherwise expected. The results of Experiment 2 weaken the possibility of this explanation in two ways. First, if our participants were following a strict ratio rule, and if everyone participating had at least a small positive valuation for the Hershey's, then the choice share of the free chocolate should have been 100 percent, or at least 100 percent of those selecting any chocolate, which is not the case. Second, even a less strict version of the ratio rule implies that the price reduction of the high-end chocolate from $15 \pitchfork$ to $10 \notin$ (a 33-percent price reduction) should have had a much larger effect on its share than the price reduction from $15 \$$ to $14 \$$ (a 7 -percent price reduction). This prediction did not bear out, as there was no real difference in the demand changes when the prices were reduced from $1 \& 15$ to $0 \& 14$ on the one hand, and to $0 \& 10$ on the other hand. 


\section{Experiment 3: Cafeteria.}

One possible shortcoming of Experiment 2 is that the differences between conditions were not confined to prices; the size of the transaction costs associated with the three options differed among conditions. Taking a free Hershey's or buying nothing meant not only a zero monetary price, but also freedom from the hassle of looking for change in one's pocket or backpack. If transaction cost is a large consideration in our setting, this could lead to a choice pattern favoring the Hershey's when its cost is zero (in the $0 \& 14$ and $0 \& 10$ conditions), but not when both options involve a positive cost and hence a larger transaction cost (the $1 \& 15$ condition). An initial indication that transaction costs might not be the driver of the effect in our setting can be gained from the results of the hypothetical choices in Experiment 1. Experiment $1 \mathrm{did}$ not involve real transactions and hence did not involve any transaction costs, suggesting that the results will survive a situation without transaction costs. However, while these results are suggestive, it is also possible that when respondents made their hypothetical choices, they also considered the transaction costs that would have been present if the choice they were facing had been real. Because the results of Experiment 1 could not be interpreted conclusively, and because transaction costs may be an important alternative explanation, we conducted Experiment 3, designed explicitly to control for possible differences in transaction costs. In this experiment, the physical transaction costs were held constant for the three choices (high- and low-value chocolates and no purchase) and between cost and free conditions.

Method. The experiment was carried out as one of the regular promotions at one of MIT's cafeterias, using customers who were already buying products at the cafeteria, and adding the cost of the chocolate to their bill as would be done for any other purchase in the cafeteria. By adding the cost to an existing purchase we created a situation where the chocolate purchase did not add anything to the transaction costs in terms of taking out one's wallet, looking for money, paying, etc. 
The procedure of the experiment was generally similar to that used in Experiment 2: A box with two compartments, one containing Hershey's and the other containing Lindt, was placed next to the cashier. There was a large sign that read "one chocolate per person," and the price of each chocolate was posted next to each compartment (varying across the conditions). Customers who wanted one of the chocolates had its cost added to their bill. Thus, the transaction costs in terms of payment were the same whether a customer purchased a chocolate, got a chocolate for free, or purchased nothing, because she had to pay for the main purchase anyway.

The prices were manipulated by charging $1 \pitchfork$ for Hershey's and $14 \$$ for Lindt in the cost condition $(1 \& 14)$, and $0 \$$ and $13 \$$, respectively, in the free condition $(0 \& 13)$. The price signs (conditions) were switched approximately every 40 minutes with a 10minute break between the experimental sessions. In this setting it was difficult to separate customers who decided not to participate from those who did not notice the offer; therefore, all the customers who passed by the cashier and did not select any of our chocolates were coded as "nothing." In total, 232 customers took part in this experiment.

Results and Discussion. As can be seen in Figure 4, in the $0 \& 13$ condition the demand for Hershey's increased substantially [t(189) $=4.7, \mathrm{p}<0.001]$, while the demand for Lindt decreased substantially $[\mathrm{t}(206)=-3.2, \mathrm{p}=0.001]$. If we take those who were coded as "nothing" out of the analysis, the share of Hershey's increased from 21 percent in the $1 \& 14$ condition to 71 percent in the $0 \& 13$ condition, while the share of Lindt decreased from 79 percent in the $1 \& 14$ condition to 29 percent in the $0 \& 13$ condition $[\mathrm{t}(92)=5.6, \mathrm{p}<0.0001]$.

Thus, the zero-price effect was not eliminated when transaction costs were the same for all options and in both conditions, providing strong evidence that the zeroprice effect is not produced solely by the difference in transaction costs. 


\section{Summary of the Initial Experiments}

The initial experiments presented here contrasted the choices respondents made when prices for both options were positive, with the choices they made when both options were discounted by the same amount such that the cheaper option became free. This methodology allowed us to examine the reaction to zero price, showing both an increase in demand for the cheaper product and a decrease in demand for the more expensive product. We termed this effect the zero-price effect.

Experiment 1 demonstrated that a $1 \$$ difference in price has an enormous influence on demand if it is a difference between a positive and a zero price, but not if it is a difference between two positive prices. Participants reacted as if a free Hershey's had more intrinsic value than a positively priced Hershey's. Experiment 2 validated this finding with real choices, while providing evidence against the ratios argument. Finally, Experiment 3 demonstrated that the zero-price effect was not driven by transaction costs. Thus, we have demonstrated that, just as in many other domains, in the domain of prices, zero is treated qualitatively different from other numbers.

When we ask how zero might be different from other numbers, there are two general possible answers. The first answer, based on the model proposed above, assumes that a unique benefit to the price of zero leads to the demand discontinuity at zero. A second approach is to model this process with concave utility of money. In such a model, instead of evaluating options by V - P (that is, value minus price), consumers evaluate them by $\mathrm{V}-v(\mathrm{P})$, where $v$ is the prospect theory value function (Kahenman and Tversky, 1979). To illustrate this point, consider, for example, the choices from Experiment 3: If the net benefit of a chocolate is defined by $\mathrm{V}-v(\mathrm{P})$, then participants could switch from Lindt to Hershey's because $v(14 ф)-v(13 \nsubseteq)<v(1 \pitchfork)$. Of course, there is no question that the utility of money is likely to be generally concave (Kahenman and Tversky, 1979), so the question for our purpose is not whether the utility of money is concave but rather whether concavity could account for our findings. Moreover, it is clear that the discontinuity at zero proposed here is a special case of concavity. After all, a function that is zero at zero, then has a jump, and then is upward sloping and linear, is 
concave. The question is, therefore, whether the effect of the price of zero documented here is captured better by a continuous or discontinuous concave utility of money.

To examine the possibility that continuous concavity could be sufficient to account for the results, consider the contrast between the two price reductions in Experiment 1: the one that reduced the price of the cheaper chocolate from $2 \$$ to $1 \$$ (the reduction from $2 \& 27$ to $1 \& 26)$ and the one that reduced the price of the cheaper chocolate from $1 \notin$ to $0 \$$ (the reduction from $1 \& 26$ to $0 \& 25$ ). A model claiming that a continuous concave utility function of money can account for the results would have to assume that individuals evaluate the options by $\mathrm{V}-v(\mathrm{P})$, that $v(26 థ)-v(25 \Phi)<v(1 థ)$, and that this difference is sufficient to explain the large zero-price effect documented in Experiment 1. At the same time, this model would also have to assume that $v(27 ф)$ $v(26 థ)<v(2 \$)-v(1 \$)$, allowing for an increase in the demand for Hershey's and a decrease in the demand for Ferrero when moving from the $2 \& 27$ condition to the $1 \& 26$ condition. Such demand changes should be smaller in magnitude than the ones between $1 \& 26$ and $0 \& 25$, but they would have to be in the same direction. However, as can be seen in Figure 2, the results do not indicate anything of that kind. Thus, while concavity is clearly present in the utility of money, it seems that the type of concavity observed in our setting is more likely to be brought about by a discontinuity at zero than by continuous concavity alone (an experiment with Amazon gift certificates described later in the paper will provide further support to the discontinuous nature of the zero-price model.)

As a final comment, it is worthwhile to point out one arbitrary aspect of the zeroprice model we have sketched. In this model, we formalized the discontinuity of zero as an additional benefit in the utility of a free good. The predictions and results would hold just as well if, instead, we were to formulate this idea as extra negative utility (cost) of positively priced items. 


\section{Why is Zero Price Special?}

In the first part of this paper, we demonstrated that zero price has a special role in consumers' cost-benefit analysis. In this section we will take one step toward exploring the psychology behind the zero-price effect. In particular, we consider three possible explanations that we label "Social Norms," "Mapping Difficulty," and "Affect." Based on prior research (and one additional experiment), we argue that the Social Norms explanation, although applicable in some cases, cannot fully account for the zeroprice effect in our setup, and thus we focus on distinguishing between the Mapping Difficulty and the Affect explanations. Overall, the results support the role of affect as the main cause of the effect of zero in this setup.

\section{Social Norms}

One possible psychological mechanism that could be underlying the zero-price effect deals with the norms that might accompany free products. The basic idea is that costly options invoke market-exchange norms, while free products invoke norms of social exchange (Fisks, 1992). These social norms can create a higher value for the product in question than would otherwise prevail. One example of this idea was provided by Heyman and Ariely (2004), who demonstrated that individuals are likely to exert higher effort under a social contract (when no monetary amounts are mentioned) than when small or medium monetary amounts are mentioned. Another example of the relationship between social norms (not mentioning prices) and exchange norms (mentioning prices) was provided by Ariely, Gneezy, and Haruvy (2005), who examined the behavior of individuals faced with a large box of candies with one of two offers: Either the candy was free, or the candy had a nominal price (1థ or $5 \notin)$. Not surprisingly, the results showed that when the cost was zero, many more students took candy than when the price was positive. More interestingly, when the price was zero, the majority of the students took one and only one candy, while those who took candy when it had a cost took a much larger amount (effectively creating lower demand as prices decreased). 
Together, these results suggest that, in general, social norms are more likely to appear when price is not a part of the exchange. The appearance of these social norms could lead to an increased valuation for the good and hence an increased market-share for the free chocolate in our experiments. However, one other condition in Heyman and Ariely's experiments suggests that the effect of social norms may not apply to our settings. This important condition included elements of both the social exchange (a gift) and the monetary exchange, by giving participants a candy but telling them the cost of the candy (for example, "Here is a $50 \$$ candy bar"). When both elements were present, the results were very similar to those of the monetary exchange (and therefore different from those of the social exchange). Relating these findings to our setting suggests that it is highly unlikely that participants would apply social-exchange norms to one option in the choice set (the free option) and monetary-exchange norms to the other option in the choice set (the costly option). Instead, it much more likely that participants applied the same set of norms to all the choices in the choice set, thereby eliminating the effect of the social-exchange norms.

To further test the ability of social-exchange norms to account for the zero-price effect, we aimed to create an additional condition that would allow us to disassociate the free cost from the social norms invoked by having no price. To do so, we created a condition in which the low-valued chocolate was offered for a small negative price $(-1 థ)$. The logic behind this condition is that a small negative price creates a transaction with no downside (no financial cost), while at the same time mentioning money and thus presumably not invoking social-exchange norms. Thus, to the extent that the zero-price effect is due to the social nature of non-monetary exchanges, a negative price, having no social aspect, should not induce an increase in the intrinsic valuation of the products the way that zero price does. On the other hand, if the zero-price effect is not due to social exchange norms, the demand in this condition should be very similar to the demand in the free condition.

There were 342 subjects in the experiment. The experiment replicated the $1 \& 14$ and $0 \& 13$ conditions in Experiment 2, and added to them a $-1 \& 12$ condition, where the 
price of Hershey's was $-1 \$$ (participants were offered a Hershey's plus a penny) and the price of Lindt was $12 \$$. The demand curves in the $1 \& 14$ and $0 \& 13$ conditions replicated previous findings: Compared with the $1 \& 14$ condition, the demand for Hershey's in the $0 \& 13$ condition increased substantially from 15 percent to 34 percent $[\mathrm{t}(193)=3.4, \mathrm{p}<$ 0.001], while the demand for Lindt decreased substantially from 38 percent to 16 percent $[\mathrm{t}(212)=-3.8, \mathrm{p}<0.001]$. Of more significance, we found that when prices dropped from $0 \& 13$ to $-1 \& 12$, the demand for Lindt remained at 16 percent $[\mathrm{t}(220)=0.04, \mathrm{p}=0.97]$. It is also interesting that when the price of Hershey's decreased to $-1 \phi$, its demand increased from 34 percent to 50 percent $[\mathrm{t}(212)=-3.8, \mathrm{p}<0.001]$. Thus, in contrast to the socialexchange norms account, the zero-price effect remains when a cost is mentioned for both options in the choice set. These results also suggest that a change in the cost-benefit analysis is likely to cause the shift in valuation of the free product. This change also seems to apply to valuation of products with small negative costs.

\section{Mapping Difficulty}

A second possible psychological mechanism that might explain the overemphasis on free options is suggested by the findings of Ariely, Loewenstein, and Prelec (2003, 2006), Hsee, Zhang, and Zhang (2003), and Nunes and Park (2003), which demonstrate that people have difficulty mapping the utility they expect to get from hedonic consumption into monetary terms. In one set of studies that illustrates this mapping difficulty, Ariely, Loewenstein, and Prelec (2003) demonstrated that maximum willingness to pay (elicited by an incentive-compatible procedure) was susceptible to anchoring with an obviously irrelevant number, the last two digits of participants' social security number (Tversky and Kahneman, 1974; Chapman and Johnson, 1999). For example, students with the last two digits of their social security numbers in the bottom 20 percent of the distribution, priced a bottle of 1998 Côtes du Rhône wine at $\$ 8.64$ on average, while those with the last two digits of their social security numbers in the top 20 percent of the distribution priced the same bottle at $\$ 27.91$ on average (see also Simonsohn and Loewenstein, 2006). These results suggest that it is difficult for decision- 
makers to use their internal evaluations for products, and that, as a consequence, they resort to the use of external cues when coming up with their valuations.

Mapping difficulty could play a role in our setting in the following way. To the extent that evaluating the utility of a piece of chocolate in monetary terms is difficult, individuals might resort to a strategy that assures them at least some positive surplus.

Specifically, while getting a piece of the lower-value chocolate for free has to be a positive net gain, paying for a piece of the higher-value chocolate is less clearly so. To illustrate this point, imagine a situation in which a consumer's valuation of the lowervalue chocolate is somewhere between $1 \$$ and $5 \$$ and her valuation of the higher-value chocolate is somewhere between $10 \$$ and $20 \$$. If this consumer were faced with the $1 \& 14$ condition, it would be unclear whether any of the options would give her a net benefit. Nor would it be clear which option would give her a higher net benefit. On the other hand, the same consumer, when facing the $0 \& 13$ condition, could easily see that one of the options - the free option-would be sure to give her a net benefit; hence, that is the one she would pick. Thus, the zero-price effect might be attributed, from this perspective, to the uncertainty in overall benefit associated with costly options, and the certainty in overall benefit associated with free options.

\section{Affect}

A third possible psychological mechanism that might account for the zero-price effect has to do with affect. Affect is the idea that options with no downside (no cost) evoke a more positive affective response than options that involve both benefits and costs. To the extent that individuals use this affective reaction as a cue for their decisions, they will choose the free option (Slovic et al., 2002a; 2002b). We test this prediction directly in Experiment 5. This affective perspective also points to circumstances under which the zero-price effect could be eliminated: If the cause of the zero-price effect is a reliance on an initial (overly positive) affective evaluation, making a non-affective and more cognitive evaluation accessible might diminish the zero-price effect. 
In order to test which of these two psychological mechanisms (mapping difficulty or affect) is more likely to be the driver of the zero-price effect, we conducted three more experiments. In Experiment 4 (and its two follow-ups) we attempted to reduce or eliminate the mapping difficulty in order to observe whether this reduced mapping difficulty would diminish or eliminate the zero-price effect. In Experiment 5 we tested the first proposition of the affective account-that free offers elicit higher positive affect. In Experiment 6, we tested whether forcing individuals to evaluate their options cognitively, hence making these evaluations available and accessible, can eliminate the zero-price effect.

\section{Experiment 4: Halloween}

The goal of Experiment 4 was to test whether mapping difficulty could be driving the zero-price effect. To do so, the design of Experiment 4 and its follow-up was modified to reduce the mapping difficulty by making both sides of the transactions (benefits and costs) commensurable. Our prediction was that, to the extent that mapping difficulty was the cause of the zero-price effect, the effect would be diminished when the two sides of the transaction were of the same type. We also predicted that this type of manipulation would have no bearing if the cause of the zero-price effect was due to evoking of affect by a price of zero.

Method. To reduce mapping difficulty we offered participants the opportunity to buy chocolate in exchange for chocolate rather than money. In particular, on Halloween, 34 trick-or-treaters at the house of one of the authors were exposed to a new Halloween tradition. As soon as the kids knocked on the door, they were given three Hershey's (each weighing about $0.16 \mathrm{oz}$ ) and were asked to hold the Hershey's they had just received in their open hand in front of them. Next, each kid was offered a choice between a small $(1 \mathrm{oz})$ and a large $(2 \mathrm{oz})$ Snickers bar. In the free $(0 \& 1)$ condition, the kids were told that they could have the small Snickers bar or exchange one of their Hershey's for the large Snickers bar. In the cost (1\&2) condition, the kids were told that 
they could exchange one of their Hershey's for the small Snickers bar or exchange two for the large Snickers bar. They could also choose not to make any exchanges.

Results and Discussion. As can be seen in Figure 5, the zero-price effect remained strong even when the tradeoffs involved commensurate products and exchange currency. In the condition where the small Snickers bar was free, the demand for it increased substantially (relative to the cost condition), while the demand for the large Snickers bar decreased substantially $[\mathrm{t}(31)=4.9, \mathrm{p}<0.001]$. A follow-up experiment, with adults, was later conducted at the Student Center in a setting similar to Experiment 2, and with prices $0 \& 4$ and $1 \& 5$ Hershey's for the small and the large Snickers, respectively. The results replicated the pattern of results of the Halloween experiment.

These results generalize the previous results in five ways. First and foremost, they demonstrate that the attractiveness of zero cost is not limited to monetary transactions; there seems to be a general increase in attractiveness of options that do not require giving anything up. Second, the results hold when goods and exchange currency are commensurate, both being chocolate-based candy (for other results regarding commensurability, see Ariely et al., 2003; Hsee, Zhang, and Zhang, 2003; Nunes and Park, 2003). Third, while a $1 \$$ price is not very common in the marketplace, the choice and trading of candy is more common (particularly in the context of Halloween), adding real-world validity to the finding. Fourth, the results provide further support for the notion that the physical hassle involved in transactions (taking money out of one's wallet, for example) cannot account for the results. Fifth, the results show that this effect holds for adults as well as for kids.

As a further test of the mapping explanation for the effect of zero prices, we conducted an experiment where both the products and the method of payment were money (not chocolate). The two products to choose from were \$10 and \$20 Amazon gift certificates (there was also a "neither" option). The prices for the gift certificates were varied at three levels; $\$ 5$ and $\$ 12, \$ 1$ and $\$ 8$, and $\$ 0$ and $\$ 7$, respectively, with the $\$ 20$ 
certificate always costing $\$ 7$ more than the $\$ 10$ certificate. As the reader may have guessed by now, there were no differences in demand patterns between the $5 \& 12$ and the $1 \& 8$ conditions $[\mathrm{t}(65)=0.53, \mathrm{p}=0.6]$, but the demand for the $\$ 10$ certificate rocketed in the $0 \& 7$ condition $[t(65)=6.9, \mathrm{p}<0.001]$, with the demand for the $\$ 20$ certificate going to zero (see Figure 6). The similarity in demand between the $5 \& 12$ and the $1 \& 8$ conditions, together with the large shift in demand in the $0 \& 7$ condition, also points against a ratio explanation. The ratios of the costs are much more favorable toward the $\$ 10$ Amazon gift certificate in the $1 \& 8$ condition than in the $5 \& 12$ condition (by about 3.3 times); if respondents had been using a ratio rule, we should have observed a large increase in demand for the $\$ 10$ Amazon gift certificate in the $1 \& 8$ condition, which we did not.

In summary, the main reason to conduct the Halloween and the Amazon gift certificate experiments was to test whether the difficulty of mapping money onto experiences could be the cause of the zero-price effect. To test this idea, we first replaced money as the exchange medium with chocolates, which are presumably more naturally mapped onto other chocolates. We then replaced the product and the exchange medium with money. The results demonstrate that the zero-price effect is not limited to goodsfor-money exchanges, and that it is unlikely to be fully explained by the difficulty-ofmapping explanation.

\section{Experiment 5: Smileys}

The affect account that was proposed earlier has two basic components. The first is that zero-price offers evoke higher positive affect. The second is that people use this affect as an input for their decision-making process. Experiment 5 examined the first component-that people would experience more positive affect when facing a free offer than when considering other offers.

Method. We asked 243 participants to evaluate how attractive they found an offer of a chocolate at a certain price. Four different offers were made across 
participants: a Hershey's for free (H0), a Hershey’s for $1 \$(H 1)$, a Lindt for $13 \$(L 13)$ and a Lindt for $14 \$$ (L14). Participants were given a questionnaire with the details of the offer and a picture of the chocolate. At the bottom of the page, schematic pictures of five faces ("smileys") with different expressions were shown, varying from unhappy to very happy. Participants were asked to indicate their feelings towards the offer by circling one of the faces. If participants' attitude toward the offers reflected only the net benefits of the offers, then the attitudes towards L14 and H1 should be slightly lower than those towards L13 and H0, respectively, and the difference between the attitudes towards L13 and L14 should be close to that between $\mathrm{H} 0$ and H1. The affect argument suggests that the attitude towards $\mathrm{H} 0$ should be much more positive than the attitude towards any other offer.

Results and Discussion. The results are depicted in Figure 7. In line with the affect hypothesis, the attitude toward the $\mathrm{H} 0$ offer was significantly more positive than the attitude toward any other offer $[\mathrm{t}(113)=7.0, \mathrm{p}<0.001]$. At the same time, there was no difference among the attitudes toward the other three offers $[F(2,178)=0.35, p=0.7]$. Thus, in line with the affect idea, the free good elicited more positive affect than would be predicted by the standard cost-benefit analysis.

\section{Experiment 6: Forced Analysis}

Given the high affective reaction to the free option shown in Experiment 5, the second component to be tested is that this increased affect is being used by individuals as a cue for their decisions, and that this use of affect is the cause of the zero-price effect. To test this possibility, Experiment 6 forced individuals to engage in a cognitive and deliberate evaluation of the alternatives before making their choices. By doing so, we made a non-affective and more cognitive evaluation available and accessible to participants when making their choices. We assume that under these conditions participants are more likely to base their evaluations on these cognitively available inputs and consequently to place a lower weight on the affective evaluations. To the 
extent that the cause of the zero-price effect is the affective component, such reliance on cognitive inputs should dramatically reduce the zero-price effect.

Method. Two hundred students filled out a survey in which they were asked to make a hypothetical choice among three options. We also asked half of the subjects to answer two questions before making the choice. The design was a 2x2, (Chocolates' Prices: $1 \& 14$ vs. 0\&13) x (Survey Type: Neutral vs. Forced Analysis), between-subjects design. The surveys in the $1 \& 14$ conditions started with the following introduction: "Imagine that there is a chocolate promotion at the checkout counter of your supermarket. You can either buy one Hershey's kiss for 1థ or one Lindt truffle for 14థ." Participants in the [1\&14, Neutral] condition were then immediately asked to circle their preferred option (a Hershey's for $1 \$$, a Lindt for $14 \$$, or neither). The $0 \& 13$ condition was the same as the $1 \& 14$ condition, except that Hershey's and Lindt were offered for $0 \notin$ and $13 \$$, respectively. Before making their choice, participants in the [1\&14, Forced Analysis] condition were first asked the following two questions: "On a scale from 1 (Not at all) to 7 (Much more) how much more do you like the Lindt truffles in comparison with Hershey's kisses?" and "On a scale from 1 (Not at all) to 7 (Much more) how much more would you hate paying $14 \$$ in comparison with paying 1 \&?" Participants had to circle a number from 1 to 7 , anchored at 1 (Not at all), 4 (About the same) and 7 (Much more). After answering these questions, participants were asked to make their hypothetical choice between the two options. The $0 \& 13$ condition was the same as the $1 \& 14$ conditions, except that Hershey's and Lindt were offered for $0 \$$ and $13 \$$, respectively.

Results and Discussion. To start, we ran two logit regressions with the proportions of subjects buying Hershey's and Lindt as the dependent variables and the answers to the two scaled questions as independent variables. Unsurprisingly, preferring Lindt to Hershey's was negatively related to choosing Hershey's $[z=3.1, p<$ $0.01]$, and positively to choosing Lindt $[z=3.0, p<0.01]$. At the same time, disliking paying more was positively related to choosing Hershey's $[z=3.2, p=0.001]$, and 
negatively to choosing Lindt $[\mathrm{z}=3.1, \mathrm{p}<0.01]$. Thus, participants' answers to the questions were in line with their choices.

Next we performed two ANOVAs with the proportions of subjects choosing Hershey's and Lindt as the dependent variables; the independent variables were the chocolates' prices, the survey type, and the interaction of the two. The ANOVAs revealed significant main effects of the chocolates' prices [for Hershey's $F(1,196)=9.7$, p $<0.01$; for Lindt $\mathrm{F}(1,196)=8.7, \mathrm{p}<0.01$; no main effects of the survey type [for Hershey's $F(1,196)=2.0, p=0.2$; for Lindt $F(1,196)=1.6, p=0.2]$, and, most importantly, a significant interaction effect of the two factors [for Hershey's $F(1,196)=4.5 p=0.03$; for Lindt $[F(1,196)=5.1, p=0.02]$.

As can be seen in Figure 8, the zero-price effect was replicated in the Neutral conditions (for Hershey's [t(97) =3.7, $\mathrm{p}<0.001]$; for Lindt $[\mathrm{t}(97)=-3.7, \mathrm{p}<0.001]$ ), but not in the conditions where subjects were forced to compare the options on the relevant dimensions (quality and price) before making their choice. In the Forced Analysis conditions, the direction of the effect is the same, but the magnitude is much smaller and statistically insignificant (for Hershey's [t(99) $=0.7, \mathrm{p}=0.5]$; for Lindt $[\mathrm{t}(99)=-0.6, \mathrm{p}=$ $0.6])$.

These results support the basic affect mechanism we proposed, where the affect evoked by the free option drives the zero-price effect; but, once people have highly available cognitive inputs, they base their decisions on those valuations, and the benefit of zero largely dissipates.

One other interpretation of these results is that, in three of our four conditions, subjects act "rationally." These are the two Forced Analysis conditions and the $[1 \& 14$, Neutral] condition. The [0\&13, Neutral] condition causes them to act based on the affect evoked by the zero price. In support of this idea, there were no significant differences among subjects' choices in the three above-mentioned conditions [for Hershey's $\mathrm{F}(2$, 147) $=0.7, \mathrm{p}=0.5$; for Lindt $\mathrm{F}(2,147)=0.7, \mathrm{p}=0.5]$, while the free condition was significantly different from the other three [for Hershey's, $t(83)=3.8, p<0.001$; for Lindt, $t(83)=3.7$, $\mathrm{p}<0.001]$. 


\section{General Discussion}

We started with two models, one that treated zero as just another price, and one that assumed that free options were evaluated more positively than other options. We proposed a method to distinguish between these two approaches and demonstrated in three experiments that the latter model was better able to account for the data. Experiment 1 provided the initial evidence in favor of the zero-price model. Experiment 2 demonstrated the effect in an actual buying setup and showed that the effect could not be due to participants' making decisions based on cost-benefit ratios. Experiment 3 showed that the effect could not be due to physical transaction costs.

After demonstrating the unique properties of zero price, we attempted to examine the psychological causes of this effect. We proposed three possible mechanisms, "Social Norms," Mapping Difficulty," and "Affective Evaluations." We discarded the "Social Norms" explanation, based on the findings (Heyman and Ariely, 2004) that, once price is mentioned, market-based transaction norms are probably invoked for all choices, making our setup unlikely to invoke social norms for the zero-price option. We further discredited the ability of this account to explain our findings, using negative prices that involve no cost but do invoke prices. We then carried out three experiments aimed at exploring which of the other two possible explanations was valid. Experiment 4 weighed against the mapping difficulty explanation. Experiments 5 and 6 provided support for the affective evaluation hypothesis.

In general, this research joins a larger collection of evidence, showing that zero is a unique number, as shown by the fact that reward, price, and probability have unique properties when they take on the value of zero. While the results of the current work suggest that the zero-price effect might be better accounted for by affective evaluations than by social norms or mapping difficulty, it is clear that zero and the price of zero offer a complex and rich domain, and that these forces are likely to operate in a variety of ways, depending on the situation and setup. In addition to these, other effects of zero might include inferences about quality, changes to signaling to the self and others, the 
effect of zero price on barriers to trial, and the ability of zero prices to create habits. Much work is needed to understand the complexities of zero prices in the marketplace.

\section{Alternative Explanations and Boundary Conditions}

One of the limitations of our experimental setups is that they were restricted to relatively cheap products and to decisions that were relatively unimportant. Given this limitation, it is an open question whether the zero-price effect would be observed when the decisions involve greater sums of money and more important decisions. To answer this question, at least partially, we conducted a survey where participants responded to one of four hypothetical scenarios about purchasing an LCD flat panel TV. In these scenarios, participants were informed that they were entitled to a large discount and that they had narrowed down their options to two: a cheaper 17" Philips and a more expensive 32" Sharp. The four conditions varied on the prices of the TVs: The Sharp was always about $\$ 600$ more expensive than the Philips, and the prices of both sets were reduced by about $\$ 100$ across conditions. From most expensive to least expensive, the conditions were: 299\&898, 199\&798, 99\&698, and 0\&598. Comparing demand across these conditions, the results $(n=120)$ generally resembled our previous findings. The demand for the smaller, cheaper TV was 40 percent in the $299 \& 898$ condition, 40 percent in the 199\&798 condition, 43 percent in the $99 \& 698$ condition, and 83 percent in the 0\&698 condition. Similarly, the demand for the larger, more expensive TV was 40 percent in the $299 \& 898$ condition, 33 percent in the $199 \& 798$ condition, 43 percent in the $99 \& 698$ condition, and 17 percent in the $0 \& 698$ condition. Overall, these results show that a shift in demand is apparent only when the price is reduced to zero $[F(3,98)=3.24, p$ $<0.05]$; otherwise, the effects of price reduction do not seem to have a large influence on the relative demand for the two TVs $[F(2,69)=0.06, p=0.94]$. While these results suggest that the effect of the price of zero is not limited to small prices and meaningless decisions, some simple thought experiments suggest that the effect might not be as simple with large consequential decisions. For example, imagine a setup where we replaced Hershey's and Lindt with Audi and Honda, and we changed the prices from 
$\$ 28,000$ and $\$ 20,000$ to either $\$ 8,100$ and $\$ 100$, or to $\$ 8,000$ and $\$ 0$, respectively. We suspect that under such circumstances, relatively small prices such as $\$ 100$ might be perceived as within a "JND" (just noticeable difference) of zero, and hence the effect of the price of zero might be stretched to accommodate this price as well. Thus, the question of what prices people perceive as zero might not be so simple, as the answer most likely relates to the context of the decision and to the magnitude of the original prices.

Another possible limitation of our setup (which was pointed out by one of the referees) is that our positive prices could have been "suspicious." People might not be accustomed in general to prices of $1 \$, 13 \downarrow$, or $14 \$$. However, free samples are often a part of a promotion, and therefore people might be more used to them. Note that we selected such odd prices because we wanted to change the prices by a very small amount and we did not want one of the prices to involve a different level of change (25ф) relative to the discounted prices $(24 \$)$. As a result of these prices and the suspicion they may have evoked, our participants could have been making negative quality inferences about the cheap chocolates (expiration date, for example), but not about the free chocolates. One piece of evidence against this line of argument is the result of the Amazon gift certificates experiment, where the quality of the gift certificates was unlikely to be influenced by the particular price. Another example against this line of argument is the Halloween experiment, where all tradeoffs were equally strange. Still, to test this possible alternative account more directly, we conducted another survey, where participants were asked to make a hypothetical choice between a Hershey's, a Lindt, and nothing. This time we made all the prices less suspicious $-0 \& 15$ and $10 \& 25$. The results replicated previous findings, with the demand for Hershey's increasing from 8 percent in the $10 \& 25$ condition to 65 percent in the $0 \& 15$ condition, and the demand for Lindt decreasing from 45 percent in the $10 \& 25$ condition to 6 percent in the $0 \& 15$ condition. Yet, the fact that the zero-price effect does not seem to have been driven by the oddities of the prices we used does not imply that the zero-price effect will never interact with processes relating to consumers' inferences about quality. In fact, it is highly likely that, 
in many market situations, consumers might make inferences about the expected quality of the product based on the very small magnitude of the prices and, more importantly, based on the price of zero itself, or on the availability of free giveaway promotions (Simonson, Carmon, and O'Curry, 1994).

Finally, one other possible explanation for our findings (again, we thank a reviewer for pointing this out to us) could be the asymmetric dominance effect (Huber, Payne, and Puto, 1982). In our free conditions, the cheaper product (Hershey's in most cases) always weakly dominated one of the other alternatives-buying nothing - since they shared the same cost (zero) and were clearly different in terms of their benefits. At the same time, in the cost conditions, there was not such an asymmetric dominance relationship. If the zero-price effect in our setup was driven by the asymmetric dominance effect, this would mean that the relationship between the option to buy nothing and the option of choosing the cheaper chocolate (whether it was a dominance relationship or not) was the basic cause of the effect. It also means that by excluding the option to not buy anything, we would be eliminating the asymmetric dominance relationship, and that any effect due to this relationship should be eliminated.

In order to test the asymmetric dominance explanation, we conducted a survey ( $n=136)$ where we did not include the option to not buy anything (of course, we could only do this in a hypothetical survey) and contrasted the zero-price effect in this case to the case where individuals had the option to not buy anything. The results replicated the standard finding, showing that the free Hershey's had a demand boost (increasing from 28 percent to 92 percent) while the Lindt had a demand decrease (from 72 percent to 8 percent) even in the absence of a dominated alternative. Moreover, these changes in demand were basically identical to the case where there was the option to select nothing. Thus, while asymmetric dominance is an unlikely explanation for our findings, the more general questions of what context effects might be involved with prices of zero and what context effects might influence prices of zero are open and interesting questions. 


\section{Managerial Implications.}

The most straightforward managerial implication of our findings concerns the increased valuations for options priced at zero. This means that when considering promotions at a low price, companies might consider further discounts to zero-a decrease that is likely to have a surprisingly larger effect on demand. At least one piece of anecdotal evidence supports this claim. When Amazon introduced free shipping in some European countries, in France the price was mistakenly reduced not to zero but to one French Franc-a negligible positive price (about 10\$). It turned out that whereas the number of orders increased dramatically in the countries that introduced free shipping, not much change was observed in France.

Another possible implication of the effect of zero might be in the domain of food intake. When designing food and drink products, companies can decide whether to create low caloric content (or fat, or carbs, etc.) or whether to try to reduce these values further, to zero. Assuming that the effect of zero would generalize to other domains as well, investing further effort in creating a product with zero grams of fat, for example, might have a very positive influence on demand.

Decisions about zero might be more complex, but also more relevant, in domains where there are multiple dimensions, each of which can be set separately but where all are consumed together. In the domain of prices, these might be cars or computers, where the price is composed of a sum of multiple components, and where some might be set at a standard price and some might be priced at zero. In the domain of food and drink these might be calories, grams of fat, carbohydrates, amount of lead, etc., where some might be set at a standard amount and some might be set at zero. To the extent that the effect of zero holds for individual dimensions each of which is only a part of a complete product, it might be beneficial to consider the effect of zero at this level as well. 


\section{Appendix}

The offers across experiments and conditions.

\begin{tabular}{|c|c|c|c|c|}
\hline Experiment & DV & Condition & Low-value good & High-value good \\
\hline \multirow{3}{*}{ Experiment 1} & \multirow{3}{*}{$\begin{array}{l}\text { Hypothetical } \\
\text { choice }\end{array}$} & $0 \& 25$ & Hershey's kiss for $0 ₫$ & Ferrero Rocher for $25 \phi$ \\
\hline & & $1 \& 26$ & Hershey's kiss for $1 \$$ & Ferrero Rocher for $26 \$$ \\
\hline & & $2 \& 27$ & Hershey's kiss for $2 \$$ & Ferrero Rocher for $27 \phi$ \\
\hline \multirow{3}{*}{ Experiment 2} & \multirow{3}{*}{ Real choice } & $0 \& 14$ & Hershey's kiss for $0 \notin$ & Lindt Truffle for $14 \phi$ \\
\hline & & $0 \& 10$ & Hershey's kiss for $0 ₫$ & Lindt Truffle for $10 \phi$ \\
\hline & & $1 \& 15$ & Hershey's kiss for $1 \phi$ & Lindt Truffle for $15 \phi$ \\
\hline \multirow{2}{*}{ Experiment 3} & \multirow{2}{*}{ Real choice } & $0 \& 13$ & Hershey's kiss for $0 ₫$ & Lindt Truffle for $13 \phi$ \\
\hline & & $1 \& 14$ & Hershey's kiss for $1 \phi$ & Lindt Truffle for $14 \phi$ \\
\hline \multirow{3}{*}{$\begin{array}{l}\text { Negative } \\
\text { Price }\end{array}$} & \multirow{3}{*}{$\begin{array}{l}\text { Hypothetical } \\
\text { choice }\end{array}$} & $-1 \& 12$ & Hershey's kiss plus $1 \$$ & Lindt Truffle for $12 \phi$ \\
\hline & & $0 \& 13$ & Hershey's kiss for $0 \notin$ & Lindt Truffle for $13 \phi$ \\
\hline & & $1 \& 14$ & Hershey's kiss for $1 \$$ & Lindt Truffle for $14 \phi$ \\
\hline \multirow{2}{*}{ Experiment 4} & \multirow{2}{*}{ Real choice } & $0 \& 1$ & $\begin{array}{l}\text { Small Snickers for } 0 \\
\text { Hershey's }\end{array}$ & $\begin{array}{l}\text { Large Snickers for } 1 \\
\text { Hershey's }\end{array}$ \\
\hline & & $1 \& 2$ & $\begin{array}{l}\text { Small Snickers for } 1 \\
\text { Hershey's }\end{array}$ & $\begin{array}{l}\text { Large Snickers for } 2 \\
\text { Hershey's }\end{array}$ \\
\hline \multirow{3}{*}{$\begin{array}{c}\text { Amazon Gift } \\
\text { certificates }\end{array}$} & \multirow{3}{*}{ Real choice } & $0 \& 7$ & $\$ 10$ Amazon GC for $\$ 0$ & $\$ 20$ Amazon GC for $\$ 7$ \\
\hline & & $1 \& 8$ & $\$ 10$ Amazon GC for $\$ 1$ & $\$ 20$ Amazon GC for $\$ 8$ \\
\hline & & $5 \& 12$ & $\$ 10$ Amazon GC for $\$ 5$ & $\$ 20$ Amazon GC for $\$ 12$ \\
\hline \multirow{4}{*}{ Experiment 5} & \multirow{4}{*}{ Attitude } & H0 & Hershey's kiss for $0 ₫$ & - \\
\hline & & H1 & Hershey's kiss for $1 \$$ & - \\
\hline & & L13 & - & Lindt Truffle for $13 \phi$ \\
\hline & & L14 & - & Lindt Truffle for $14 \$$ \\
\hline \multirow{4}{*}{ Experiment 6} & \multirow{2}{*}{$\begin{array}{l}\text { Hypothetical } \\
\text { choice }\end{array}$} & 0\&13, Basic & Hershey's kiss for $0 \$$ & Lindt Truffle for $13 \phi$ \\
\hline & & 1\&14, Basic & Hershey's kiss for $1 \$$ & Lindt Truffle for $14 \phi$ \\
\hline & \multirow{2}{*}{$\begin{array}{l}\text { Hypothetical } \\
\text { choice and } \\
\text { ratings }\end{array}$} & $\begin{array}{l}\text { 0\&13, Forced } \\
\text { Analysis }\end{array}$ & Hershey's kiss for $0 \notin$ & Lindt Truffle for $13 \$$ \\
\hline & & $\begin{array}{l}\text { 1\&14, Forced } \\
\text { Analysis }\end{array}$ & Hershey's kiss for $1 \$$ & Lindt Truffle for $14 \$$ \\
\hline
\end{tabular}




\section{References}

Ariely, D., Gneezy, U., and Haruvy, E. (2005). Social norms and the price of zero. Unpublished manuscript, MIT.

Ariely, D., Loewenstein, G., and Prelec, D. (2003). Coherent arbitrariness: Stable demand curves without stable preferences. The Quarterly Journal of Economics, 118(1), 73105.

Ariely, D., Loewenstein, G., and Prelec, D. (2006). Tom Sawyer and the construction of value. Journal of Economic Behavior and Organization, 60, 1-10.

Bem, D.J. (1965). An experimental analysis of self-persuasion. Journal of Experimental Social Psychology, 1(3), 199-218.

Chapman, Gretchen B. and Eric J. Johnson. (1999). Anchoring, activation, and the construction of values. Organizational Behavior and Human Decision Processes, 79, 115-153.

Deci, E.L. and Ryan, R.M. (1985). The general causality orientations scale: Selfdetermination in personality. Journal of Research in Personality, 19(2), 109-134.

Festinger, L. and Carlsmith, J.M. (1959). Cognitive consequences of forced compliance. Journal of Abnormal and Social Psychology, 58, 203-210.

Fiske, A.P. (1992). The four elementary forms of sociality: Framework for a unified theory of social relations. Psychological Review, 99, 689-723.

Gneezy, U. and Rustichini, A. (2000a). A fine is a price. Journal of Legal Studies, 29(1), 1-18.

Gneezy, U. and Rustichini, A. (2000b). Pay enough or don't pay at all. Quarterly Journal of Economics, 115(2), 791-810.

Heyman, J. and Ariely, D. (2004). Effort for payment: A tale of two markets. Psychological Science, 15(11), 787-793.

Hsee, C.K., Yu, F., Zhang, J., and Zhang, Y. (2003). Medium maximization. Journal of Consumer Research, 30(1), 1-14.

Huber, J., Payne, J.W., and Puto, C. (1982) Adding asymmetrically dominated alternatives: violations of regularity and the similarity hypothesis. Journal of Consumer Research, 9(1), 90-98.

Kahneman, D. and Tversky, A. (1979). Prospect theory: An analysis of decision under risk. Econometrica, 47(2), 263-291.

Lepper, M.R., Greene, D., and Nisbett, R.E. (1973). Undermining children's intrinsic interest with extrinsic reward: A test of the "overjustification" hypothesis. Journal of Personality and Social Psychology, 28(1), 129-137.

Nunes, J.C. and Park, C.W. (2003). Incommensurate resources: Not just more of the same. Journal of Marketing Research, 40(4), 26-38.

Simonsohn U. and Loewenstein G. (2006). Mistake \#37: The effect of previously faced prices on current housing demand. The Economic Journal, 116(1), 175-199.

Simonson, I., Carmon, Z., and O'Curry S. (1994). Experimental evidence on the negative effect of product features and sales promotions on brand choice. Marketing Science, 13, 23-40. 
Slovic, P., Finucane, M., Peters, E., and MacGregor, D.G. (2002a). The affect heuristic. In T. Gilovich (ed.), Heuristics and Biases: The Psychology of Intuitive Judgment (pp. 397-420). New York: Cambridge University Press.

Slovic, P., Finucane, M., Peters, E., and MacGregor, D.G. (2002b). Rational actors or rational fools: Implications of the affect heuristic for behavioral economics. Journal of Socio Economics, 31(4), 329-342.

Tversky, A. and Kahneman, D. (1974). Judgment under uncertainty: Heuristics and biases. Science, 185, 1124-1131. 
Table 1: Predictions of the standard cost-benefit model and a model that includes overreaction to zero. The table illustrates the predictions when prices for two products go from $\left[\mathrm{Px}_{\mathrm{X}} \mathrm{P}_{\mathrm{Y}}\right]$ (where $\mathrm{Px}<\mathrm{P}_{\mathrm{Y}}$ ) to $\left[0, \mathrm{P}_{\mathrm{Y}} \mathrm{P} x\right]$, respectively.

\begin{tabular}{|c|c|c|c|}
\hline & & Standard cost-benefit model & Zero price model \\
\hline \multirow{3}{*}{$\begin{array}{l}\text { Changes in } \\
\text { Valuations }\end{array}$} & Costs & \multicolumn{2}{|c|}{ Both costs decrease by the same amount } \\
\hline & Benefits & Both benefits remained the same & $\begin{array}{l}\text { Benefit of the low-value good } \\
\text { increases }\end{array}$ \\
\hline & $\begin{array}{c}\text { Net } \\
\text { benefits }\end{array}$ & $\begin{array}{c}\text { Net benefits increase by the same } \\
\text { amount }\end{array}$ & $\begin{array}{l}\text { Net benefit of the low-value good } \\
\text { increases more }\end{array}$ \\
\hline \multirow{4}{*}{\multicolumn{2}{|c|}{ Changes in demands }} & \multicolumn{2}{|c|}{ Some switching from nothing to something } \\
\hline & & No switching between goods & $\begin{array}{c}\text { Some switching from high-value } \\
\text { to low-value good }\end{array}$ \\
\hline & & $\begin{array}{l}\text { Demand for the low-value good } \\
\text { increases }\end{array}$ & $\begin{array}{l}\text { Demand for the low-value good } \\
\text { increases }\end{array}$ \\
\hline & & $\begin{array}{l}\text { Demand for the high-value good } \\
\text { increases }\end{array}$ & $\begin{array}{c}\text { Demand for the high-value good } \\
\text { decreases }\end{array}$ \\
\hline
\end{tabular}




\section{Figure captions}

Figure 1: Groups of consumers choosing options $\mathrm{X}, \mathrm{Y}$, and $\mathrm{N}$ as prices go down from $\left[\mathrm{Px}_{\mathrm{P}} \mathrm{P}_{\mathrm{y}}\right]$ to $\left[\mathrm{Px}_{-\varepsilon}, \mathrm{P}_{\mathrm{Y}-\varepsilon}\right]$ as predicted by the standard economic model with linear utilities and the zero-price model.

Panel A presents the demand distribution when prices are $[\mathrm{Px}, \mathrm{P} y]$.

Panel B presents the changes in groups of consumers choosing options $\mathrm{X}, \mathrm{Y}$, and $\mathrm{N}$ when prices are reduced from $\left[\mathrm{Px}_{\mathrm{X}} \mathrm{P}_{\mathrm{Y}}\right]$ to $\left[\mathrm{Px}_{\mathrm{x}} \varepsilon, \mathrm{P}_{\mathrm{Y}-\varepsilon}\right]$.

Panel $\mathrm{C}$ presents the changes in groups of consumers choosing options $\mathrm{X}, \mathrm{Y}$, and $\mathrm{N}$ when prices are reduced from $\left[\mathrm{Px}_{\mathrm{X}} \mathrm{P}_{\mathrm{y}}\right]$ to $\left[0, \mathrm{PY}_{\mathrm{Y}} \mathrm{Px}\right]$ under the assumptions of the standard model.

Panel D presents the same changes as in Panel C under the assumptions of the zeroprice model.

Figure 2: Proportions of individuals choosing the Hershey's and the Ferrero Rocher chocolates across the three experimental conditions in Experiment 1.

Figure 3: Proportions of individuals choosing Hershey's and Lindt across the three experimental conditions in Experiment 2.

Figure 4: Proportions of individuals choosing Hershey's and Lindt across the two experimental conditions in Experiment 3.

Figure 5: Proportions of individuals choosing the small and large Snickers Bars across the two experimental conditions in Experiment 4.

Figure 6: Proportions of individuals choosing the $\$ 10$ and $\$ 20$ Amazon gift certificates across the three experimental conditions in the follow-up to Experiment 4 .

Figure 7: Affective ratings of the four offers in Experiment 5.

Figure 8: Proportions of individuals choosing Hershey's and Lindt across the experimental conditions in Experiment 6. 


\section{Figure 1}
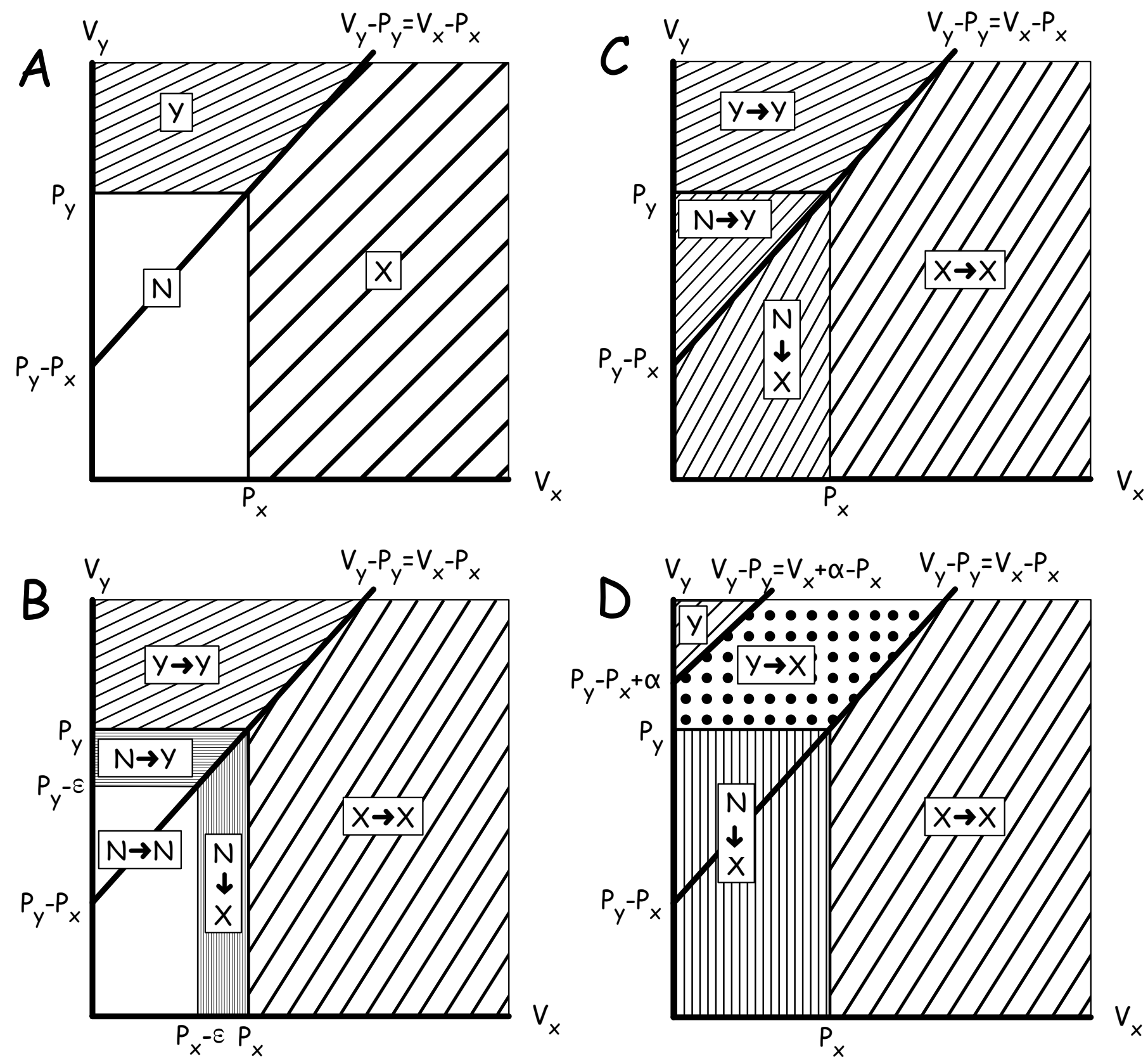
Figure 2

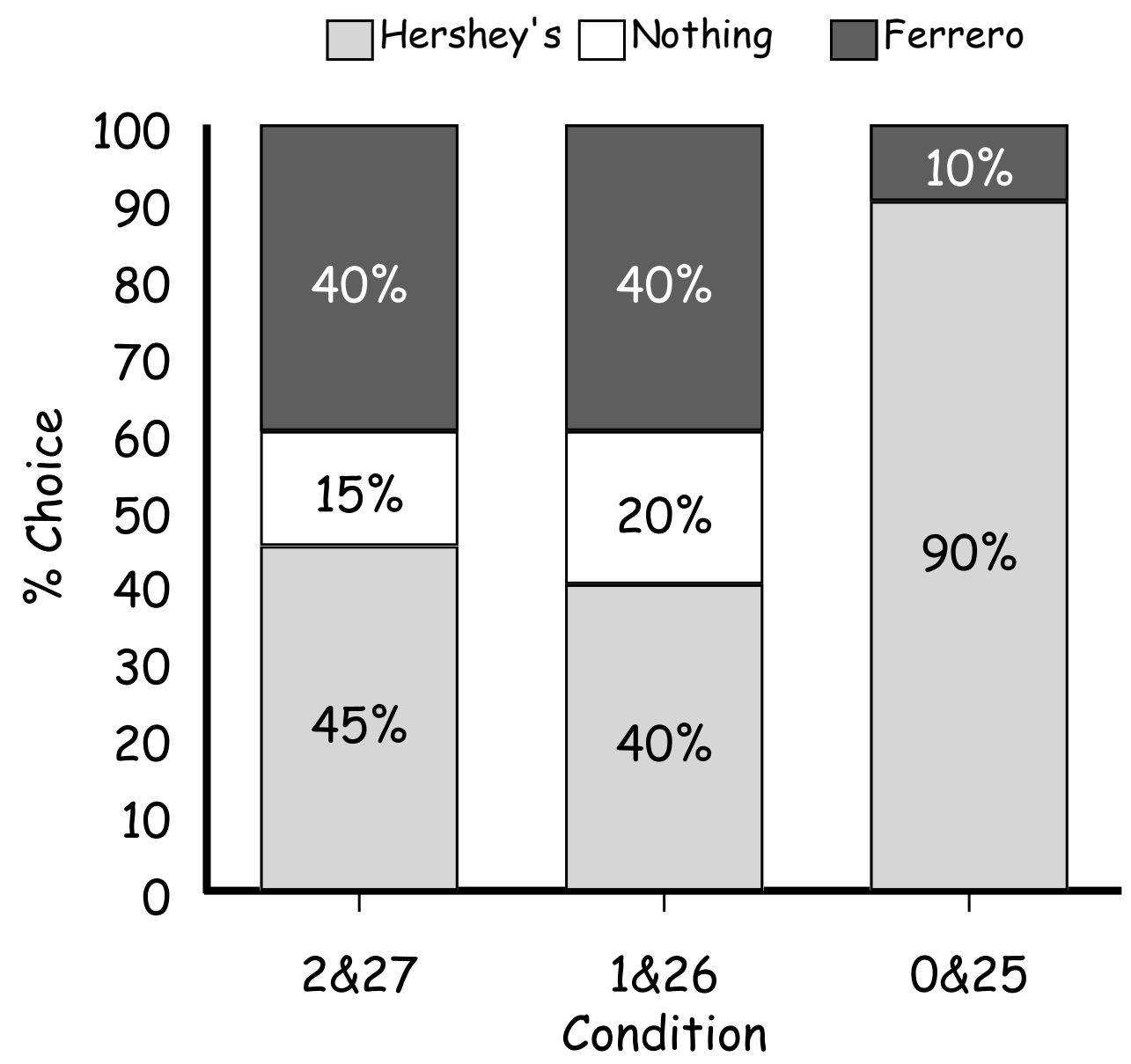


Figure 3

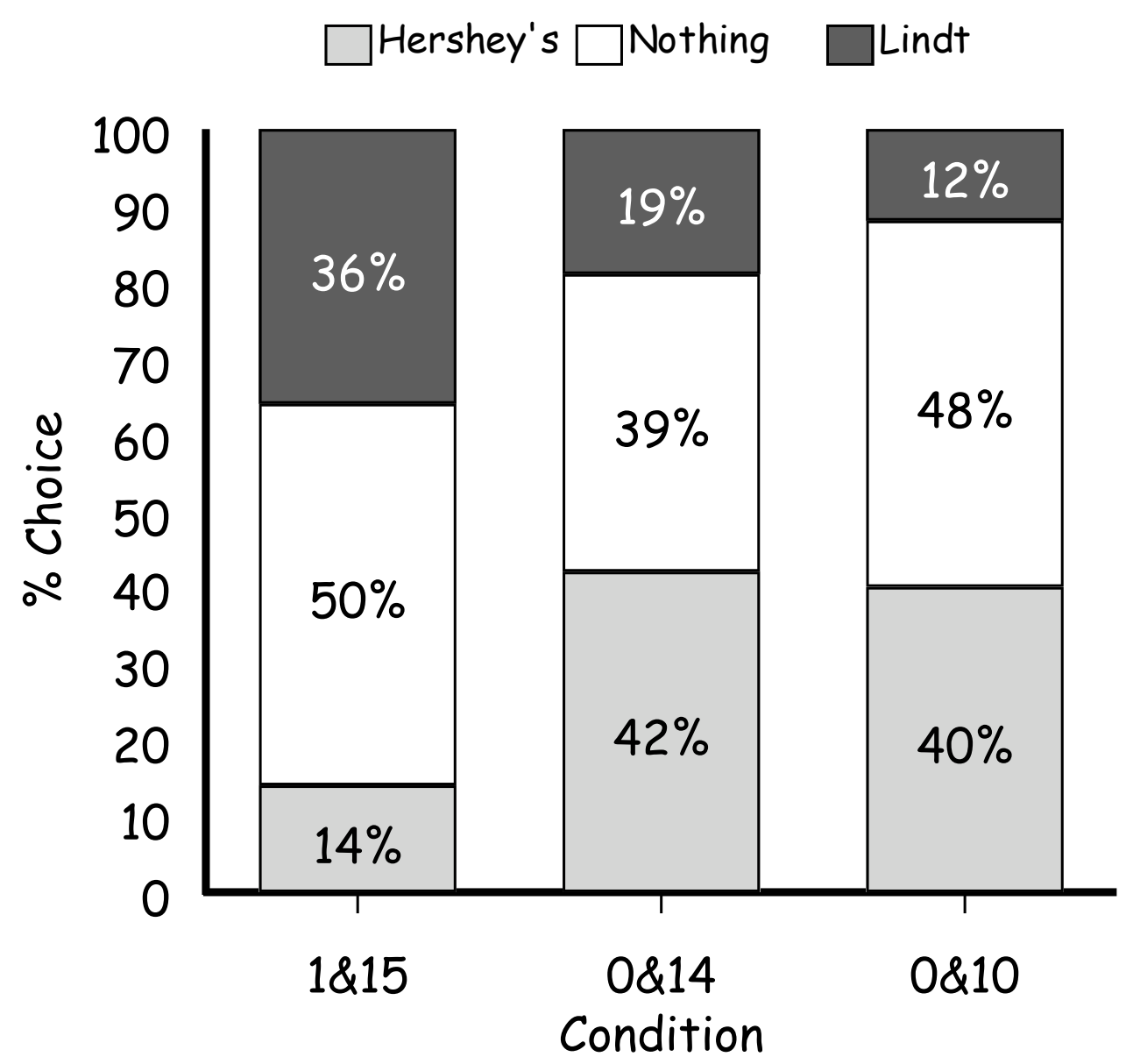


Figure 4

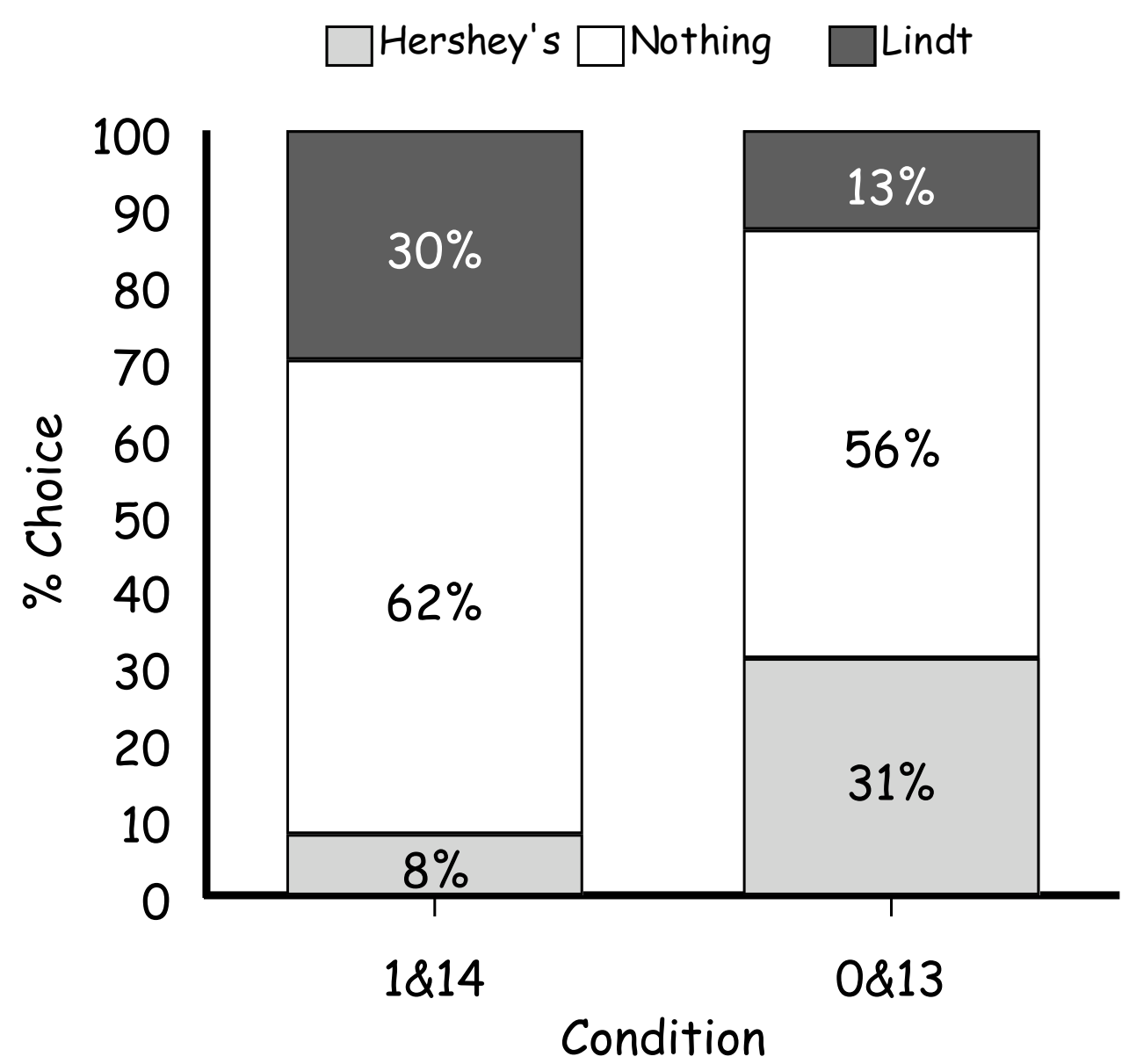


Figure 5

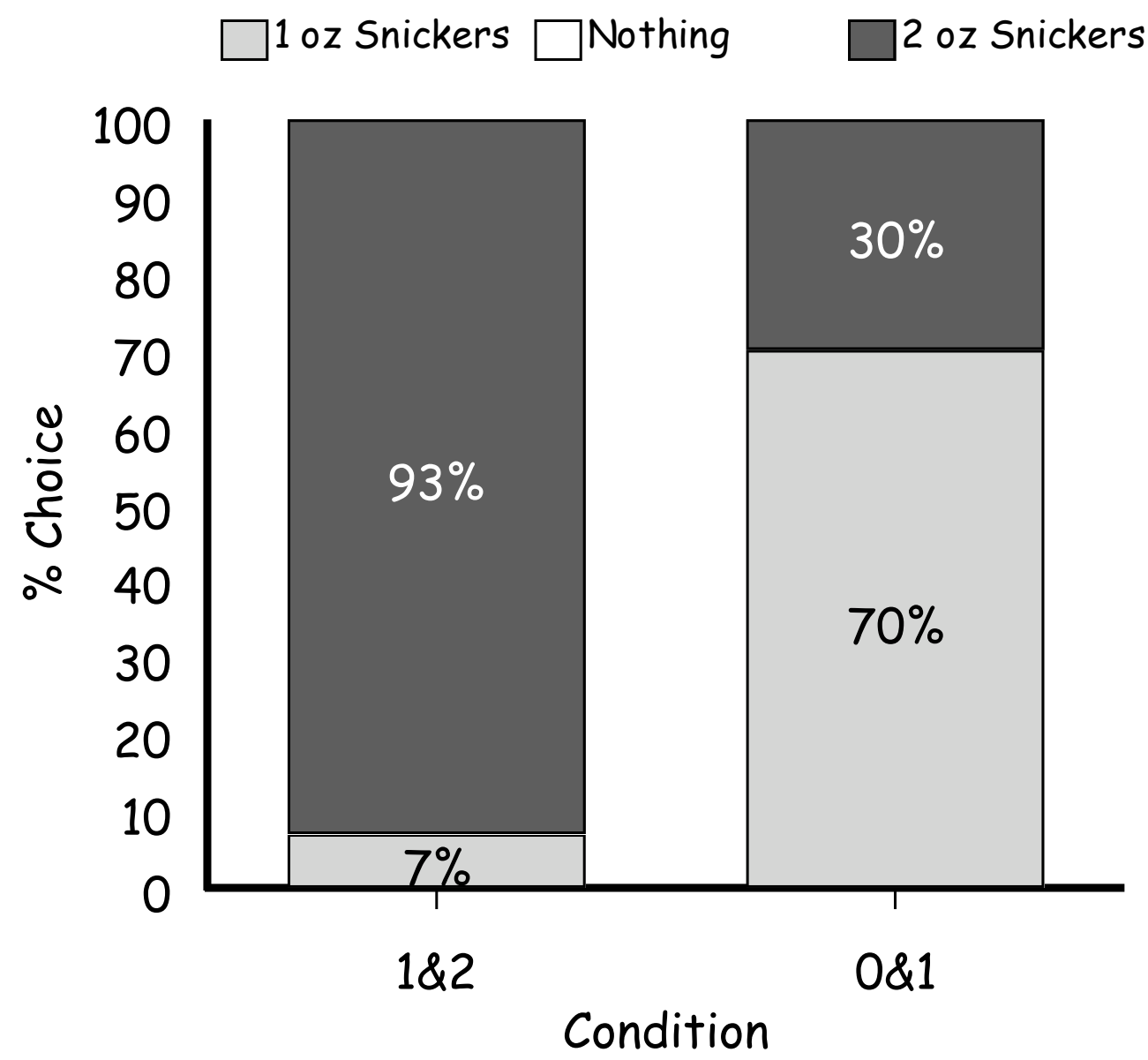


Figure 6

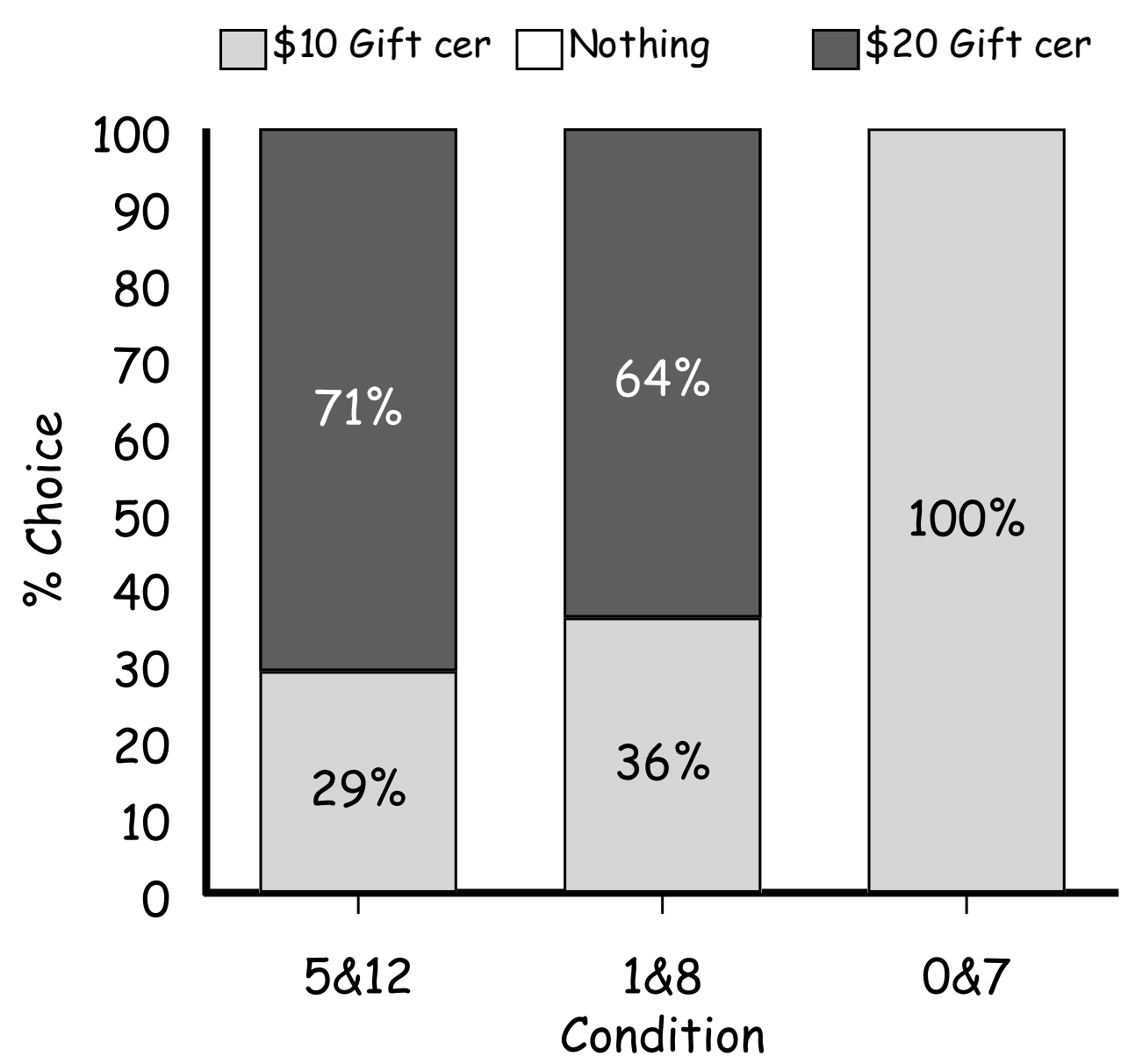


Figure 7

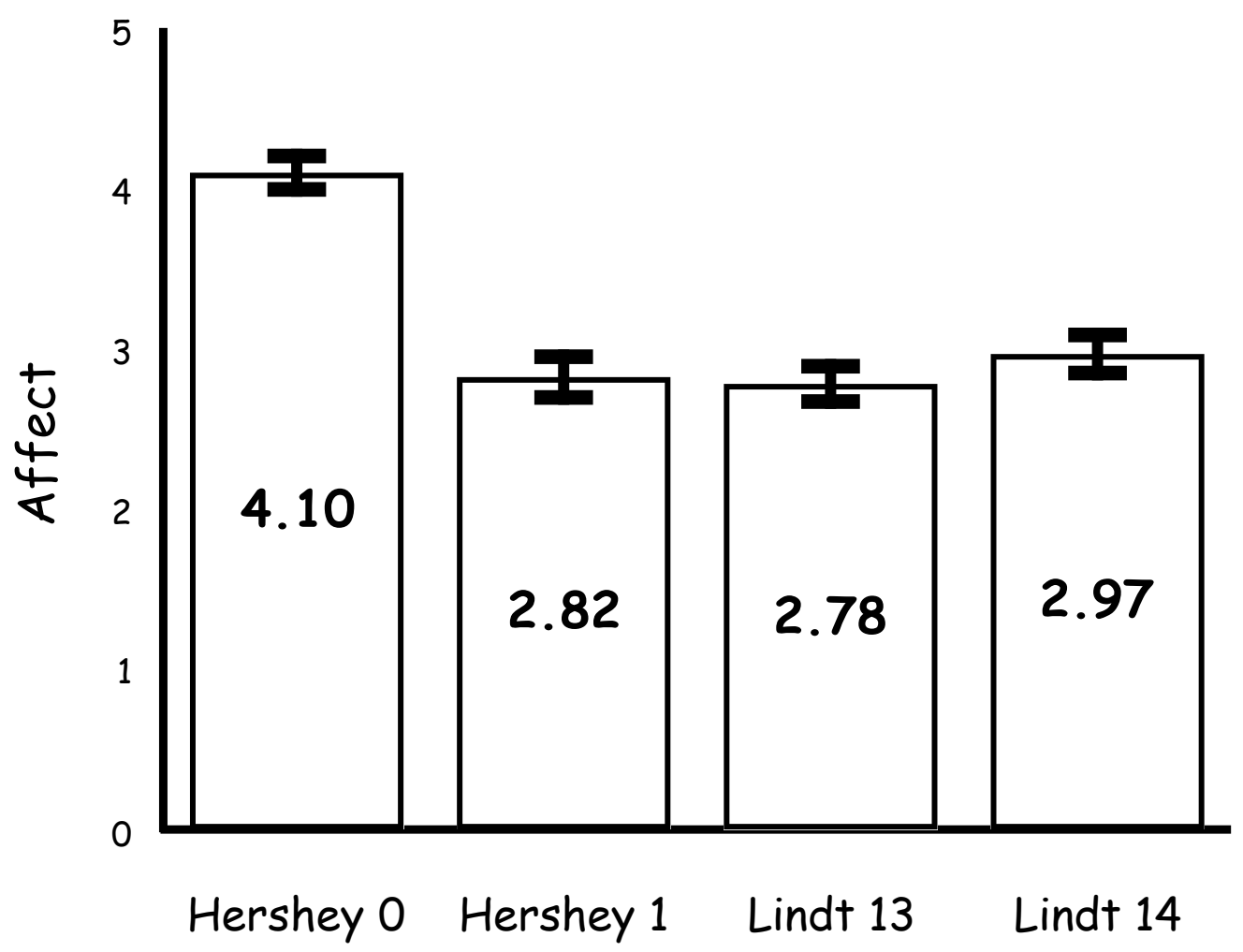


Figure 8

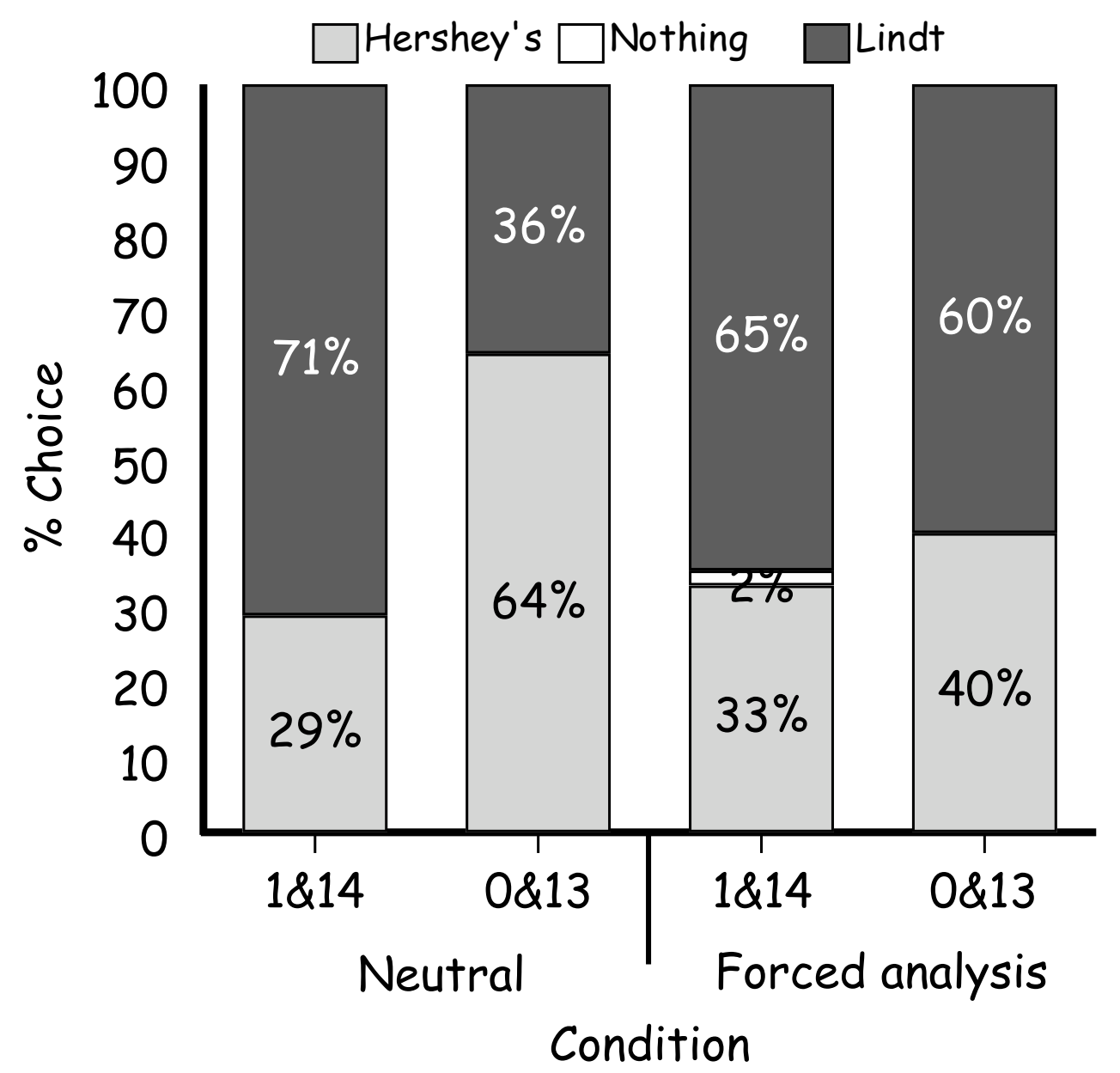

